\title{
Mossy fiber distribution in four lines of rats: A correlative study with avoidance abilities and excitability thresholds
}

\author{
NATASCIA DIMITRIEVA \\ I. P. Pavlov Institute of Physiology, Academy of Sciences, Leningrad, U.S.S.R. \\ STEFANO GOZZO \\ Istituto di Psicobiologia e Psicofarmacologia, CNR, Rome, Italy \\ YURI DIMITRIEV \\ I. P. Pavlov Institute of Physiology, Academy of Sciences, Leningrad, U.S.S.R. \\ and \\ MARTINE AMMASSARI-TEULE \\ Istituto di Psicobiologia e Psicofarmacologia, CNR, Rome, Italy \\ and Laboratoire de Physiologie Nerveuse, CNRS, Gif-sur-Yvette, France
}

\begin{abstract}
The distribution of the mossy fiber terminals in the hippocampal regio inferior was studied by the histochemical sulfide silver Timm method in four lines of rats selected for high (HAS) or low (LAS) avoidance scores and for high (HET) or low (LET) excitability thresholds of the neuromuscular apparatus. The results showed that HAS subjects, which have been found to exhibit the absolute lower excitability threshold, have significantly fewer mossy fibers in the infrapyramidal layers - that is, on the basal dendrites of the CA3 pyramidal cells-than did the three other groups. This observation confirms previous findings indicating a negative correlation between the density of mossy fiber terminals in these layers and active avoidance abilities. Since, however, HET subjects exhibit both high avoidance scores and high excitability thresholds but also present a large density of mossy fiber terminals in the infrapyramidal layer, the hypothesis of a direct relationship between few mossy fiber projections on basal dendrites of pyramidal cells and high avoidance scores must probably be revised.
\end{abstract}

The correlations existing between genetically associated brain characteristics and specific behaviors represent useful models for the comparative investigation of relationships between brain structures and behavioral functions. It has been observed that significant variations of volume and size of the hippocampus and of the neocortex in mice underlie differences in activity, exploration rate, and discrimination performances (Wimer \& Prater, 1966; Wimer, Wimer, \& Roderick, 1971). Moreover, strain-specific distributions of the mossy fiber boutons-which correspond to the projection from the granule cells of fascia dentata to the pyramidal cell dendrites of the hippocampal regio inferior and can be visualized by using the Timm method for heavy metals-have been found to correlate with various active avoidance abilities. In particular, a strong negative correlation has been observed between the density of mossy fiber

The authors are indebted to Mario Sansone for critically reading the manuscript. They also wish to thank Mario Battaglia for his statistical assistance and Giuseppe Olimpieri for his photographic assistance. terminals in the intrapyramidal and/or infrapyramidal layers and the learning scores obtained by inbred mice or rats in two-way avoidance tests (Schwegler \& Lipp, 1981). This observation was recently strengthened by Schwegler, Lipp, and Van der Loos's (1981) finding of a correlation between mossy fiber patterns and active avoidance scores in individuals belonging to an outbred strain. However, as noted in the previous studies, a basic problem still remained: Did the observed correlation actually support a direct relationship between the morphological characteristics of the hippocampus and active avoidance performance, or did it indicate an undetected correlation?

Thus, it should be noted that active avoidance is a multidimensional process and that selecting animals on the basis of avoidance performance therefore implies the selection of a particular set of neurobiological and behavioral characteristics. The analysis of activity and reactivity in high- and low-avoider rats has, in fact, led to the conclusion that selection probably is based on differences in some aspects of activation, the high-avoider subjects being the most active (Holland \& Gupta, 1966). It has also been hy- 
pothesized that variations in arousal (Satinder, 1977) or association processes (Annisman, 1975) could be responsible for the quality of performance displayed by high and low avoiders. Consequently, specific patterns of mossy fiber terminals could merely be related to selected characteristics that control one or several dimensions of the active avoidance process.

Since unpublished observations by N. Dimitrieva and Y. Dimitriev have suggested that stable highavoidance performances could be exhibited not only by rats selected on the basis of high-avoidance scores but also by rats selected on the basis of the excitability threshold of the neuromuscular apparatus, we decided to analyze and to compare the distribution of mossy fiber boutons in such strains. In effect, the presence of similar patterns of mossy fiber projections in high-avoider subjects, independent of the initial criterion used for selection, would provide additional evidence concerning the existence of a correlation between the morphological properties of the regio inferior hippocampus and general activeavoidance-task performance.

\section{METHOD}

\section{Subjects}

Four lines of 90-120-day-old albino strain rats were used. Two lines, bred over 9 generations and obtained from the Rappolovo rearing center in Leningrad, were selected for high (HAS) and low (LAS) avoidance scores as assessed for each individual in a 1-day shuttle box session involving 100 trials with a 30 -sec light used as the conditional stimulus and a .5-mA, 20-sec shock used as unconditional footshock. The two other lines, bred over 12 generations, were selected from the albino K.M. strain (obtained from the rearing center of the Moscow University) for high (HET) and low (LET) excitability thresholds of the neuromuscular apparatus as determined by spaced applications of increasing rectangular shocks on the gastrocnemius of the posterior paw (Vaido \& Sitdikow, 1979). Four independent groups, each corresponding to one of the selected lines, were used (HAS, $N=3 ; \mathrm{LAS}, \mathrm{N}=3$; HET, $N=4$; LET, $N=4$ ).

\section{Procedure}

In each group, both shuttle box performances and excitability thresholds were recorded according to the previously described methods.

The subjects were then weighed, anesthetized with pentobarbital $(50 \mathrm{mg} / \mathrm{kg})$, and perfused for Timm staining according to Barber, Vaughn, Wimer, \& Wimer (1974). The brains were extracted from the skulls, fixed in a Dubosq-Brazil solution, using 37\% Formalin, and then embedded in paraffin. Serial horizontal sections were developed according to the Timm method and counterstained with hematoxylin of Mayer.

For a comparative analysis of the hippocampal mossy fiber layers, the horizontal sections to be used for quantification were selected at specific intervals between two convenient dorsoventral landmarks in the brains. The level at which the rostral (septal) and caudal (posterior) portions of the mossy fibers become discontinuous was chosen as the dorsal landmark. The level at which commissural anterior, pars anterior, disappeared medially corresponded to the ventral landmark. Sections selected for comparisons and measurements were in the 25 th (plane A), 50th (plane B), and 75th (plane $C$ ) percentile, passing from the dorsal to the ventral landmark.

The sizes of the mossy fiber terminal fields in the suprapyramidal, intrapyramidal, and infrapyramidal positions between the four

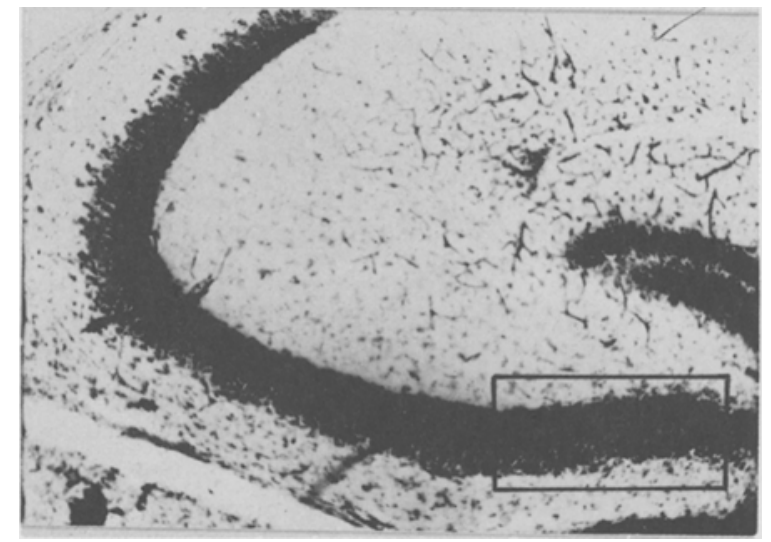

Figure 1. The area of sampling in $\mathrm{CA}$. For each subject, the area covered by mossy fiber terminals was measured planimetrically in the portion of $\mathrm{CA3}$ (plane $\mathrm{A}$ ) delimited by the dark rectangle.

lines at each of the three planes were compared. The area covered by the Timm-stained mossy fiber terminals was determined planimetrically for each case within a sampling region located in CA3 between 6.6 and $600 \mu \mathrm{m}$ from the hilus (Figure 1).

\section{RESULTS}

Behavioral and physiological measurements are given in Table 1. As would be expected from the selection criteria, avoidance scores are significantly higher in HAS subjects than in LAS subjects $(U=0$, $\mathrm{p}=.014$ ) and excitability thresholds are lower in LET subjects (which are the less excitable) than in HET subjects ( $U=4, p=.17$, marginally significant). In agreement with N. Dimitrieva and Y. Dimitriev's unpublished observations, HET subjects also exhibit significantly higher avoidance scores than LET subjects $(U=0, p=.014)$. However, it must be noted that, as a result of the two independent criteria selections, there is no difference in excitability thresholds between the LAS and HET groups, while the subjects of the HAS group display the lowest excitability thresholds among the four lines.

A Spearman rank correlation was performed between avoidance scores and excitability thresholds in groups selected for high and low values of each criterion. Although no significant correlation between the two parameters was found in the groups selected for high and low excitability thresholds $(\rho=+.61)$, a strong negative correlation was found in groups selected for high and low avoidance scores $(\rho=+.89)$.

The patterns of mossy fiber projections were then analyzed. The extents of the areas covered by the Timm-stained mossy fiber terminals in each plane and each layer for the four groups were compared by a one-way analysis of variance. The results are shown in Table 2. The areas are expressed in square microns and correspond to the mean $( \pm \mathrm{SE})$ of the measurements from the individual cases. For each case, the measure represents the mean area of mossy-fiber- 
Table 1

Active Avoidance Scores (AAS; in Percentage of Correct Responses) for Shuttle Box Performance and Excitability Thresholds (ET; in Volts) in the Four Selected Lines of Rats

\begin{tabular}{|c|c|c|c|c|c|c|c|c|}
\hline & \multicolumn{2}{|c|}{ HAS } & \multicolumn{2}{|c|}{ LAS } & \multicolumn{2}{|c|}{ LET } & \multicolumn{2}{|c|}{ HET } \\
\hline & PCR & SE & PCR & $\mathrm{SE}$ & PCR & SE & PCR & SE \\
\hline $\begin{array}{l}\text { AAS } \\
\text { ET }\end{array}$ & $\begin{array}{r}64.70 \\
0.75\end{array}$ & $\begin{array}{l}5.60 \\
0.04\end{array}$ & $\begin{array}{r}15.30 \\
107\end{array}$ & $\begin{array}{l}3.38 \\
0.05\end{array}$ & $\begin{array}{l}5.25 \\
1.05\end{array}$ & $\begin{array}{l}1.65 \\
0.13\end{array}$ & $\begin{array}{r}77.50 \\
1.22\end{array}$ & $\begin{array}{l}1.55 \\
0.03\end{array}$ \\
\hline
\end{tabular}

Note $-P C R=$ percentage of correct responses.

Table 2

Mossy Fiber Terminal Distribution (in $\mu \mathrm{m}^{2}$ ) in a Sampling Region of the Hippocampal Regio Inferior

\begin{tabular}{|c|c|c|c|c|c|c|c|c|c|c|}
\hline \multirow[b]{2}{*}{ Layers } & \multicolumn{2}{|c|}{ HAS } & \multicolumn{2}{|c|}{ LAS } & \multicolumn{2}{|c|}{ LET } & \multicolumn{2}{|c|}{ HET } & \multirow[b]{2}{*}{$\mathrm{df}$} & \multirow[b]{2}{*}{$\mathrm{F}$} \\
\hline & Mean & SE & Mean & SE & Mean & SE & Mean & $\mathrm{SE}$ & & \\
\hline \multicolumn{11}{|c|}{ Plane: A } \\
\hline $\begin{array}{l}\text { Suprapyramidal } \\
\text { Intrapyramidal } \\
\text { Infrapyramidal }\end{array}$ & $\begin{array}{r}40271.8 \\
2242.3 \\
7886.1\end{array}$ & $\begin{array}{r}3168.7 \\
877.5 \\
966.0\end{array}$ & $\begin{array}{r}23955.0 \\
6714.5 \\
21378.2\end{array}$ & $\begin{array}{l}3014.2 \\
1173.8 \\
2378.9\end{array}$ & $\begin{array}{r}22590.8 \\
6831.0 \\
20886.8\end{array}$ & $\begin{array}{l}2283.7 \\
1145.4 \\
2828.8\end{array}$ & $\begin{array}{r}26603.8 \\
6380.9 \\
19818.0\end{array}$ & $\begin{array}{l}3364.5 \\
1314.2 \\
2871.8\end{array}$ & $\begin{array}{l}3,10 \\
3,10 \\
3,10\end{array}$ & $\begin{array}{l}6.65^{*} \\
3.10 \\
5.23^{*}\end{array}$ \\
\hline Total & 50400.4 & 3250.0 & 52048.5 & 4566.7 & 50563.6 & 4294.8 & 52802.7 & 3956.4 & 3,10 & .12 \\
\hline \multicolumn{11}{|c|}{ Plane: B } \\
\hline $\begin{array}{l}\text { Suprapy ramidal } \\
\text { Intrapyramidal } \\
\text { Infrapyramidal }\end{array}$ & $\begin{array}{r}41912.4 \\
1184.1 \\
6423.5\end{array}$ & $\begin{array}{r}1809.4 \\
463.0 \\
2730.7\end{array}$ & $\begin{array}{r}32150.4 \\
2947.5 \\
18518.6\end{array}$ & $\begin{array}{l}2141.6 \\
2559.1 \\
1608.0\end{array}$ & $\begin{array}{r}31632.7 \\
1927.0 \\
17403.6\end{array}$ & $\begin{array}{l}2119.1 \\
1177.3 \\
2243.1\end{array}$ & $\begin{array}{r}30827.0 \\
3430.0 \\
19132.8\end{array}$ & $\begin{array}{l}1598.7 \\
2954.3 \\
2634.4\end{array}$ & $\begin{array}{l}3,10 \\
3,10 \\
3,10\end{array}$ & $\begin{array}{l}6.05^{*} \\
.55 \\
5.56^{*}\end{array}$ \\
\hline Total & 49520.0 & 4181.3 & 53616.5 & 3240.1 & 50988.8 & 1032.6 & 54390.5 & 2190.8 & 3,10 & 1.50 \\
\hline \multicolumn{11}{|c|}{ Plane: C } \\
\hline $\begin{array}{l}\text { Suprapyramidal } \\
\text { Intrapyramidal } \\
\text { Infrapyramidal }\end{array}$ & $\begin{array}{r}40892.0 \\
1491.3 \\
2477.7\end{array}$ & $\begin{array}{r}829.1 \\
382.5 \\
1358.1\end{array}$ & $\begin{array}{r}32955.5 \\
2897.4 \\
12963.0\end{array}$ & $\begin{array}{l}3004.6 \\
1562.2 \\
4930.5\end{array}$ & $\begin{array}{r}35941.1 \\
1219.0 \\
5527.2\end{array}$ & $\begin{array}{r}2353.3 \\
816.6 \\
2391.4\end{array}$ & $\begin{array}{r}32258.9 \\
2725.7 \\
14314.8\end{array}$ & $\begin{array}{l}1878.5 \\
1043.9 \\
4089.8\end{array}$ & $\begin{array}{l}3,10 \\
3,10 \\
3,10\end{array}$ & $\begin{array}{c}2.9 \\
.78 \\
2.9\end{array}$ \\
\hline Total & 43861.1 & 2042.2 & 48815.9 & 5287.6 & 42637.4 & 1833.2 & 44299.7 & 4089.8 & 3,10 & .5 \\
\hline
\end{tabular}

${ }^{*} p<.05$.

terminal field determined planimetrically in three consecutive sections. Examination of the mossy fiber patterns reveals no intergroup differences between the LAS, HET, and LET groups (Figures 2a, 2c, 2d). In the suprapyramidal layer, the synaptic boutons form homogeneous bands from the hilus onto the distal extremity of $\mathrm{CA} 3$ in all three planes. In the infrapyramidal layer, the terminals are less dense and are distributed in shorter and thinner bands, which progressively disappear from the dorsal to the ventral levels. In the intrapyramidal layer, numerous oblique clusters of boutons are situated mainly near the hilus and tend to connect the infrapyramidal layer to the suprapyramidal layer.

The Timm reaction in the HAS group reveals a different organization of mossy fiber terminals (Figures $2 b$ and $\left.2 b^{\prime}\right)$. In the suprapyramidal layer, the subjects of the HAS group also present laminar bands of terminals, but the area covered is significantly larger than it is in the other groups. In the intrapyramidal and infrapyramidal layers of the HAS group, both the density and the patterns of mossy fiber projections are different from those of the previously described groups. Few terminals that are organized in small, almost horizontal bundles charac- terize the HAS subjects, whereas numerous aggregates forming disorganized configurations are present in the LAS, HET, and LET subjects.

\section{DISCUSSION}

The present results primarily confirm, in a new strain of rats, previous observations (Gozzo \& AmmassariTeule, 1983; Schwegler \& Lipp, 1981; Schwegler et al., 1981) on the relationship between avoidance scores and patterns of mossy fiber projections. Subjects selected for high-avoidance performance (HAS) exhibit significantly fewer mossy fiber boutons in the infrapyramidal layers (on basal pyramidal cell dendrites) than do subjects selected for low-avoidance performances (LAS), with the main morphological differences observed in the most dorsal sections (plane A). Moreover, our data show that significant differences in extents of areas covered by terminals can also be found in the suprapyramidal layer (on apical pyramidal cell dendrites) where HAS subjects exhibit more boutons than do LAS, HET, and LET subjects.

It should be noted, however, that in spite of their different avoidance scores, LET and HET subjects 


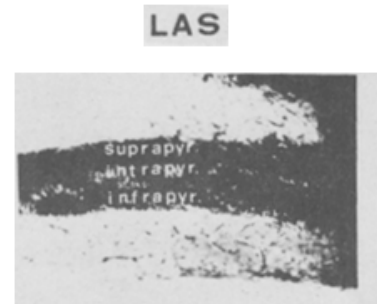

a

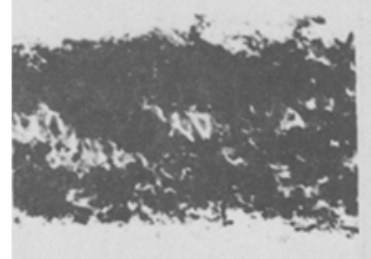

$\mathbf{a}^{\prime}$

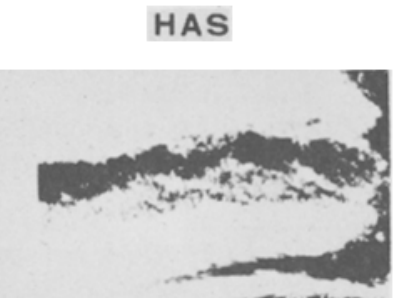

b

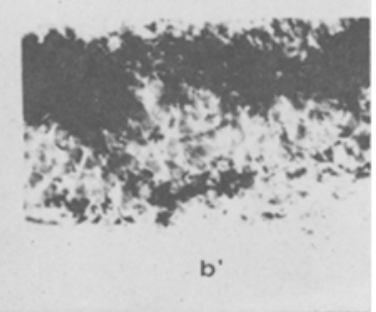

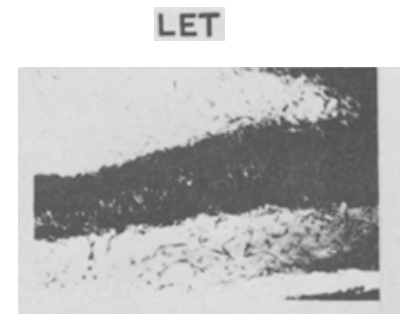

c

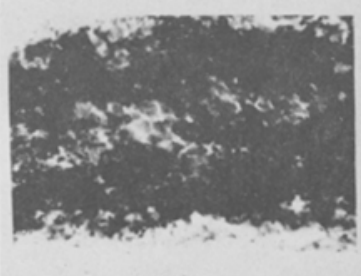

$\mathbf{c}^{\prime}$

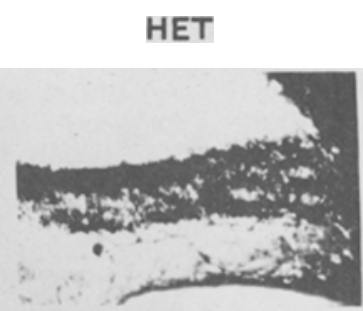

d

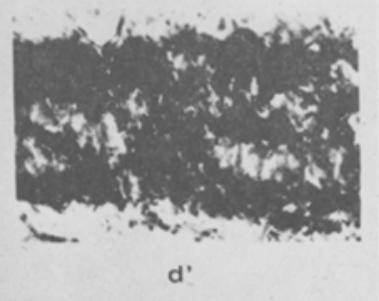

Figure 2. Typical patterns of mossy fiber terminals observed in the four groups of rats at plane A: LAS group, 2a (X96), 2a' ( $\times 240)$; HAS group, 2b ( $\times 96), 2 b^{\prime}(\times 240)$; LET group, 2c $(\times 96), 2 c^{\prime}(\times 240)$; HET group, 2d $(\times 96), 2 d^{\circ}(\times 240)$. Definitions: suprap. $=$ suprapyramidal layer, infrap. $=$ infrapyramidal layer, intiap. $=$ intrapyramidal layer.

have similar mossy fiber patterns and that the detailed laminar configurations of the terminals in these groups are more comparable to those observed in LAS than in HAS subjects (Figures $2 a^{\prime}, 2 b^{\prime}, 2 c^{\prime}$, and $2 d^{\prime}$ ). Thus, if the prediction of active avoidance scores can be inferred from the mossy fiber patterns, conversely, high avoidance scores do not necessarily imply few mossy fiber projections in the intrapyramidal and infrapyramidal layers.

This result indicates that the hypothesis of a direct correlation between few mossy fiber projections on basal dendrites of pyramidal cells and high avoidance scores must probably be revised.

In fact, the only group in which this correlation is observed, that is, the HAS group, associates a high reactivity to sensory stimulations-low excitability thresholds-with high avoidance performance. There fore, it can be assumed that selecting subjects for high-avoidance scores probably leads to the selection of particular neurobiological characteristics which could control a high sensitivity and reactivity to a nociceptive stimulus and mediate high active avoidance performances. Experimental evidence from the literature supports the hypothesis of a relationship between high avoidance scores and responsiveness to sensory stimulation (Satinder, 1976; Satinder \& Hill, 1974). With a different paradigm, it has been observed in Roman high- and low-avoider rats that the high-avoidance line-which also exhibits few mossy fiber terminals on basal pyramidal dendrites of CA3 (Schwegler \& Lipp, 1981)-is significantly more sensitive to unconditional footshocks than is the low-avoidance line.
Therefore, although unconditioned footshocks and excitability thresholds represent two distinct measures of sensitivity and/or reactivity to nociceptive stimulus, the presence of few mossy fiber terminals in the intrapyramidal and infrapyramidal layers always observed in rats selected for high avoidance scores could be primarily correlated with a high responsiveness to electric stimulations, which then could mediate good shuttlebox performance. Conversely, the high avoidance scores of HET subjects, in which high excitability thresholds were assessed, could depend on another, hitherto undetected set of neurobiological or behavioral characteristics (arousal, associative abilities) in these animals and not be related to a particular pattern of mossy fiber terminals in the regio inferior of hippocampus.

\section{REFERENCES}

Annisman, H. (1975). Differential effects of scopolamine and d-amphetamine on avoidance: Strain interaction. Journal of Comparative and Fhysiological Psychology, 3, 809-817.

Barber, R. P., Vaughn, J. E., Wimer, R. E., \& Wimer, C. C. (1974). Genetically associated variations in the distribution of dentate granule cell synapses upon the pyramidal cell dendrites in mouse hippocampus. Journal of Comparative Neurology, 156, 417-434.

Gozzo, S., \& Ammassari-Teule, M. (1983). Different mossy fiber patterns in two inbred strains of mice: A functional hypothesis. Neuroscience Letters, 36, 111-116.

Holland, H. C., \& GuPTA, B. D. (1966). Some correlated measures of activity and reactivity in two strains of rats selectively bred for differences in the acquisition of a conditioned avoidance response. Animal Behaviour, 14, 574-580.

SATINDER, K. P. (1976). Sensory responsiveness and avoidance 
learning in rats. Journal of Comparative and Physiological Psy. chology, 90, 946-957.

Satinder, K. P. (1977). Arousal explains differences in avoidance learning of genetically selected rat strains. Journal of Comparative and Physiological Psychology, 91, 1326-1336.

Satinden, K. P., \& Hilt, K. D. (1974). Effects of genotype and postnatal experience on activity, avoidance, shock threshold and open field behavior of rats. Journal of Comparative and Physiological Psychology, 86, 363-374.

Schwegle R, H., \& LiPP, H. P. (1981). Is there a correlation between hippocampal mossy fiber distribution and two-way avoidance performance in mice and rats? Neuroscience Letters, 23, 25-30.

Schwegler, H., LipP, H. P., \& VAN der Loos, H. (1981). Individual hippocampal mossy fiber distribution in mice correlates with two-way avoidance performance. Science, 214, 817-819.
Vaido, A. I., \& Sitdikow, M. K. H. (1979). Selection of rat strains by long-term threshold of excitability of the neuromuscular apparatus. Genetics (Academy of Sciences of the URSS, Leningrad), 14, 144-148.

Wimer, C., \& Prater, L. (1966). Some behavioral differences in mice selected for high and low brain weight. Psychological Reports, 25, 675-681.

Wimer, C. C., Wimer, R. E., \& Roderick, T. H. (1971). Some behavioral differences associated with relative size of hippocampus in the mouse. Journal of Comparative and Physiological Psychology, 76, 57-65.

(Manuscript received July 7, 1983; revision accepted for publication December $28,1983$. ) 